\title{
The Development of an Animal Welfare Impact Assessment (AWIA) Tool and Its Application to Bovine Tuberculosis and Badger Control in England
}

\author{
Steven P. McCulloch ${ }^{1} \cdot$ Michael J. Reiss ${ }^{2}$
}

Accepted: 30 July 2017/Published online: 19 August 2017

(C) The Author(s) 2017. This article is an open access publication

\begin{abstract}
Bovine tuberculosis (bovine TB) is a controversial animal health policy issue in England, which impacts farmers, the public, cattle and badgers. Badgers (Meles meles) act as a wildlife reservoir of disease. Policy options for badger control include (1) do nothing, (2) badger culling, and (3) badger vaccination. This paper argues for mandatory Animal Welfare Impact Assessment (AWIA) for all policy that significantly affects sentient animals. AWIA includes (1) species description, and (2) AWIA analysis stages. In this paper, AWIA is applied to impacts of bovine TB policy options on cattle and badgers. Over 4 years, 85,000 badgers will be culled to prevent the slaughter of $\sim 17,750$ cattle over 9 years. Hence, about five badgers are culled for every cow which avoids slaughter. The AWIA analyses the impact of badger vaccination on cows and badgers based on a set of stated assumptions. The AWIA estimates badger vaccination to reduce the number of cows slaughtered by 11,600 , i.e. a $12.5 \%$ reduction. Additional to the harm of killing, culling has greater welfare impacts on badgers compared to non-culling options. Actors in animal health and welfare policy were interviewed about the concept of AWIA. Policy actors supported the idea of AWIA to provide objective data to feed into policy making. The paper concludes with the proposal that AWIA is a necessary stage of just policy making where sentient animals are impacted by government policy.
\end{abstract}

Keywords Animal Welfare Impact Assessment (AWIA) - Badger culling $\cdot$ Badger vaccination $\cdot$ Bovine tuberculosis $\cdot$ Domestic cow (Bos taurus) $\cdot$ European badger (Meles meles)

Steven P. McCulloch

Steven.McCulloch@winchester.ac.uk

1 University of Winchester, Sparkford Road, Winchester SO22 4NR, UK

2 UCL Institute of Education, University College London, 20 Bedford Way, London WC1H 0AL, UK 


\section{Introduction}

The objectives of this paper are threefold. First, the paper argues for the inclusion of a mandatory formal and systematic process to assess the impacts of public policy on sentient animals. We propose and describe an Animal Welfare Impact Assessment (AWIA) tool to fulfill this role. Secondly, we apply AWIA to bovine tuberculosis (TB) policy, which is an economically important and controversial policy issue in England. Thirdly, we describe how animal health and welfare policy actors view the concept of AWIA, based on semi-structured interviewing of policy elites.

\section{The Justification for Animal Welfare Impact Assessment in Government Policy Making}

Animal health and welfare policy issues have the potential to cause considerable controversy in society. Prominent examples in the UK include foot and mouth disease, intensive farming methods and bovine tuberculosis control. Animal welfare legislation, such as the UK Animal Welfare Act 2006, has been enacted to protect the interests of sentient animals. Despite this, policymaking processes which impact animals are less stringent than those to appraise impacts on human society. In government, policy options are routinely appraised for impacts on humans and the environment by a number of formal impact assessments. These include Social Impact Assessment (SIA), Health Impact Assessment (HIA) and Environmental Impact Assessment (EIA). Economic Impact Assessment (EIA) is conducted for all policy to evaluate the economic costs and benefits of policy options (BIS 2011a, 2011b).

This paper argues for the adoption of a mandatory Animal Welfare Impact Assessment (AWIA) for all policy that significantly impacts sentient animals. We propose three arguments to support the use of mandatory AWIA:

i. Sentiency grounds moral consideration.

Sentient animals have a subjective experiential life that can go well or badly (Dawkins 2006; DeGrazia 1996; Duncan 2006). Depending on their situation, sentient animals can experience a good life or can experience suffering (FAWC 2009a). Sentiency is the ultimate ground for animal welfare legislation to protect animals' interests.

ii. To represent public concern about sentient animals.

The UK is a liberal democratic nation state and has a proud history as a leader in the compassionate treatment of animals (Radford 2001; Ryder 2000). ${ }^{1}$ The British public consistently demonstrates concern about the treatment of nonhuman sentient

\footnotetext{
$1^{1}$ For instance, Elizabeth Truss, Secretary of State for Defra, stated "I am proud that our food is produced to world-leading standards of quality, safety, traceability and animal welfare" (Truss 2015).
} 
species. $^{2}$ A legitimate democratic government should represent the interests and values of its citizens. Hence, democratic governments should have policymaking processes that accounts for the legitimate concerns and justified moral values of its citizens. The AWIA is a robust mechanism whereby government can demonstrate it is accounting for animals' interests in policy making.

iii. Animal Welfare Impact Assessment is entailed by the Treaty of Lisbon.

The Treaty of Lisbon 2009 amends the founding Treaty of the European Union. Article 13 of the Treaty of Lisbon states the following:

In formulating and implementing the Union's agriculture, fisheries, transport, internal market, research and technological development and space policies, the Union and the Member States shall, since animals are sentient beings, pay full regard to the welfare requirements of animals, while respecting the legislative or administrative provisions and customs of the Member States relating in particular to religious rites, cultural traditions and regional heritage.

We argue here that member states cannot pay full regard to animal welfare if there is no formal and systematic government policy process to facilitate this. ${ }^{3}$ The AWIA is such a formal and systematic process to account for the interests of sentient animals.

\section{Animal Welfare Impact Assessment: A Systematic Three-Stage Process}

AWIA should be conducted by government experts for all policy options that have the potential to significantly impact the interests of sentient animals. We recommend a three-stage process. Stage 1 is a species description for each species impacted by policy options. The data collected in the species description have the potential to be morally relevant and influence government decision making. Stage 2 is a harms and benefits list of impacts for all affected species for all policy options under review. Stage 3 is the AWIA analysis stage, which again is conducted for each policy option and each species impacted. The AWIA process is illustrated in Fig. 1.

\footnotetext{
${ }^{2}$ For instance, in interview, a Defra civil servant reported that the department's largest postbag has been on animal welfare issues for the last 15-20 years [Civil servant, AHVLA]. Public consultations, for instance on bovine TB and badger culling (Defra 2006b), consistently receive high response rates, which are supportive of progressive animal welfare policies. The government also regularly receives petitions on animal health and welfare issues, for instance on bovine TB and badger culling (HM Gov 2013).

3 In 2016, the British public voted in a referendum to leave the EU and at the time of writing (July 2017) it is the stated policy of the Westminster government to implement 'Brexit'. Nevertheless, the UK currently remains an EU member state. Additionally, we would argue that regardless of the UK's status with respect to the EU, mandatory AWIA is justified by the 'sentiency' and 'democratic' arguments outlined in (i) and (ii) in the main text above.
} 


\section{Species description}

Species name; common name; population number; global population; domestic/wild; human use/relation; natural lifespan; normal lifespan; population status; other important features

\section{Harms and benefits list}

List of harms and benefits of all human and nonhuman impacted groups

\section{AWIA analysis}

Positive welfare and life impacts

Negative welfare impacts and number of deaths

Fig. 1 Animal Welfare Impact Assessment

\section{Bovine TB policy in Britain}

Bovine TB has been described as the most important animal health policy issue in Britain (Defra 2011c; Reynolds 2006). ${ }^{4}$ The disease, which affects cattle, badgers and other species, is caused by the bacteria Mycobacterium bovis. Policy on bovine TB has caused considerable controversy, both in the scientific community (Bateson et al. 2012; Boyd and Gibbens 2012) and the wider public (HM Gov 2013). Policy is particularly controversial because of the Westminster government's policy to cull badgers as part of a package of control measures to reduce and ultimately eradicate bovine TB. Spencer has described how England, Wales and Scotland have three different policies to account for the role of badgers in bovine TB (Spencer 2011). ${ }^{5}$ Whereas policy in England is to cull badgers in high incidence areas, the Welsh Assembly has followed a badger vaccination policy. ${ }^{6}$ Scotland is officially bovine TB free, and thus neither culls nor vaccinates badgers. The discussion in this section and the AWIA analysis in the following section refer to badger control in England, as determined by the Westminster government.

\footnotetext{
${ }^{4}$ Deborah Reynolds was the UK Chief Veterinary Officer from 2004-2007.

5 The different policies arise principally because animal health and welfare is a devolved policy area. Defra is the department responsible for bovine TB policy in England.

${ }^{6}$ In October 2016, the Welsh government announced plans that may include the cage-trapping and culling of $M$. bovis-infected badgers on chronically infected cattle farms (Messenger 2016). The measure is in part due to the global shortage of the BCG vaccine.
} 
In 1997, the Conservative government commissioned a review of the evidence base on the contribution of badgers to bovine TB in cattle. The review, chaired by Professor John Krebs, ${ }^{7}$ found the evidence base to be insufficient to draw firm conclusions. It recommended a randomised controlled field trial to assess the impact of badger culling on bovine TB incidence in cattle (Krebs et al. 1997). The 1997 Labour government set up the Independent Scientific Group (ISG), chaired by Professor John Bourne, to conduct the Randomised Badger Culling Trial (RBCT). In its Final report, the ISG recommended against badger culling, and advised that bovine TB could be controlled and ultimately eradicated by cattle-based measures alone (Bourne et al. 2007). The government asked its Chief Scientist Advisor, Sir David King, to review the ISG's RBCT findings. The King review concluded that badger culling could indeed contribute to reducing bovine TB in cattle, provided certain measures were taken (King 2007). Despite King's report, Hilary Benn, the then Labour Secretary of State for Defra, announced in 2008 that the government would not follow a badger culling policy.

In 2010, the Conservative and Liberal Democrat Parties formed a Coalition Government. The Conservative Party, which was the dominant coalition partner, had a badger culling policy in its election manifesto. A badger culling policy was written into the Coalition Agreement (HM Gov 2010), and the government consulted on a farmer and landowner-led badger culling policy in the same year (Defra 2010a).

\section{The Pilot Badger Culls in England}

After delays due to the 2012 London Olympic Games, a legal challenge brought by the Badger Trust in the High Court and problems estimating badger numbers, two pilot badger culls were conducted in Somerset and Gloucestershire between October and December 2013. The culls were licensed for 4 years by Natural England under the Protection of Badgers Act 1992. The culls in both Somerset and Gloucestershire failed to achieve the target to cull $70 \%$ of badgers in six weeks, and both areas were granted significant extensions to their culling licences. Furthermore, the Independent Expert Panel (IEP) reported that $7.4-22.8 \%$ of badgers took over 5 min to die after being shot, which failed the government's test of this figure being under five percent (IEP 2014). The IEG was disbanded after its 2014 report on the pilot culls in Somerset and Gloucestershire in 2013, with Defra monitoring the subsequent culls.

Badger culling has continued annually in the Somerset and Gloucestershire zones, with 2016 being the fourth year of culling. Natural England granted a culling licence to an area in north Dorset in 2015, and a further seven licences have been granted for new areas in Herefordshire, Gloucestershire, Cornwall, Devon and Dorset in 2016 (BBC 2016; Defra 2016b). The following section applies AWIA to bovine TB and badger control in England. The analysis uses data from a Natural England report advising Defra on the impact of culling on badger populations in England (Natural England 2011). The data in the Natural England report includes estimates on the impact of culling on bovine TB incidence in cattle, as well as

\footnotetext{
7 Now Lord John Krebs.
} 
Table 1 AWIA species description-cow

\begin{tabular}{|c|c|c|}
\hline Category & Description & Comments \\
\hline Species name & Bos taurus & \\
\hline Common name & Cow/bull/oxen & \\
\hline Population number & $\begin{array}{l}5.308 \text { million total cattle and calves in England (Defra 2014) } \\
\text { 9.7 million total cattle and calves in UK (Defra 2013) } \\
\text { 1.78 million dairy herd in UK (DairyCo 2014a) }\end{array}$ & \\
\hline Global population & $\begin{array}{l}1.4 \text { billion (FAO 2010, p. 46) } 260 \text { million dairy cows-FAO } \\
2011 \text { in DairyCo }(2014 \text { b) }\end{array}$ & \\
\hline Domesticated/wild & Domesticated in England & \\
\hline $\begin{array}{l}\text { Human use or } \\
\text { relation }\end{array}$ & Food (milk and beef production) & \\
\hline $\begin{array}{l}\text { Natural lifespan } \\
\text { (longevity) }\end{array}$ & $\begin{array}{l}20-25 \text { years } \\
12 \text { years or older (dairy cow) (FAWC 2009b, p. 2) }\end{array}$ & \\
\hline \multirow[t]{2}{*}{$\begin{array}{l}\text { Normal lifespan } \\
\text { (average) }\end{array}$} & 6 years (FAWC 2009b, p. 9) & $\begin{array}{l}\text { Figure for dairy } \\
\text { cow }\end{array}$ \\
\hline & $1-2$ years & $\begin{array}{l}\text { Figure for beef } \\
\text { animal }\end{array}$ \\
\hline Population status & Not endangered & \\
\hline $\begin{array}{l}\text { Other important } \\
\text { features }\end{array}$ & None & \\
\hline
\end{tabular}

figures for the numbers of badgers culled. Bovine TB and badger control policy is discussed further in McCulloch and Reiss (2017a).

\section{Animal Welfare Impact Assessment (AWIA) of Bovine TB and Badger Control Policy Options}

This section applies AWIA to bovine TB and badger control policy. Three policy options are assessed:

(i) Do nothing.

(ii) Badger culling.

(iii) Badger vaccination.

Prior to the AWIA analyses, the species descriptions are provided in the section below.

\section{AWIA: Species Descriptions}

Tables 1 and 2 include species descriptions for the cow (or ox), Bos Taurus, and for the badger, Meles meles, respectively. The species descriptions include data that may influence decision making about policy options. 
Table 2 AWIA species description-badger

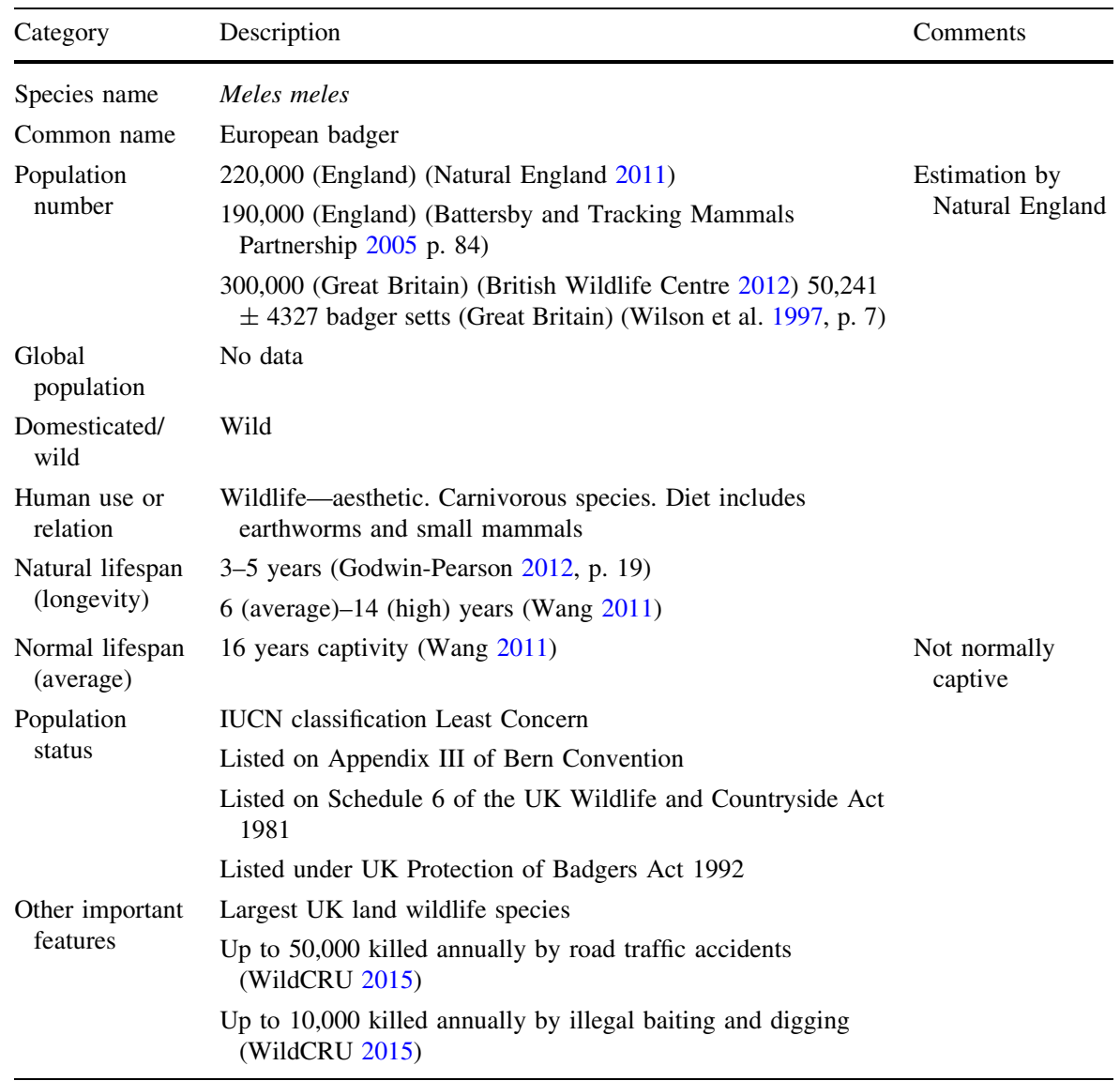

\section{AWIA Analyses}

The AWIA analyses for the three policy options are found in Tables 3, 4, 5, 6, 7 and 8. ${ }^{8}$ Much of the data in the AWIA analysis tables are taken directly or extrapolated from a Natural England ${ }^{9}$ report documenting impacts of badger culling on the badger population (Natural England 2011). Based on the Natural England report, the badger population in England is considered to be 220,000 (Natural England 2011). The AWIA analysis for badger culling is based on achieving a $19 \%$ reduction in bovine TB in cattle. The number of badgers to be culled $(85,000)$ is taken from the Natural England report, which assumes the granting of 33 cull licences using an

\footnotetext{
${ }^{8}$ The harms and benefits list stage feeds into the AWIA analyses and is not included in this paper.

${ }^{9}$ Natural England is a non-departmental public body (NDPB) sponsored by Defra. Its role is to advise the government on protecting nature for the public benefit. In the context of bovine TB policy, a principal concern of the Natural England 2011 report was to ensure that culling would not cause the local extinction of badger populations, which would be in contravention of Articles 8 and 9 of the Bern Convention.
} 


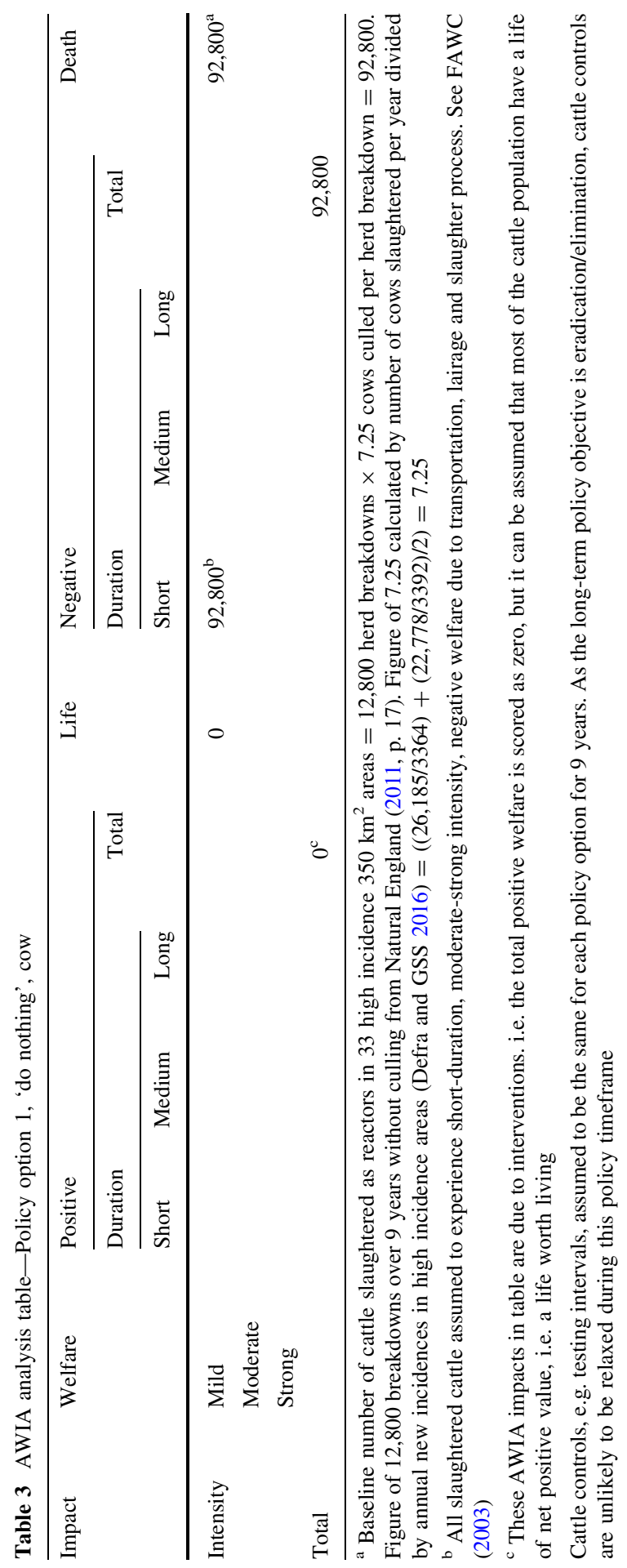




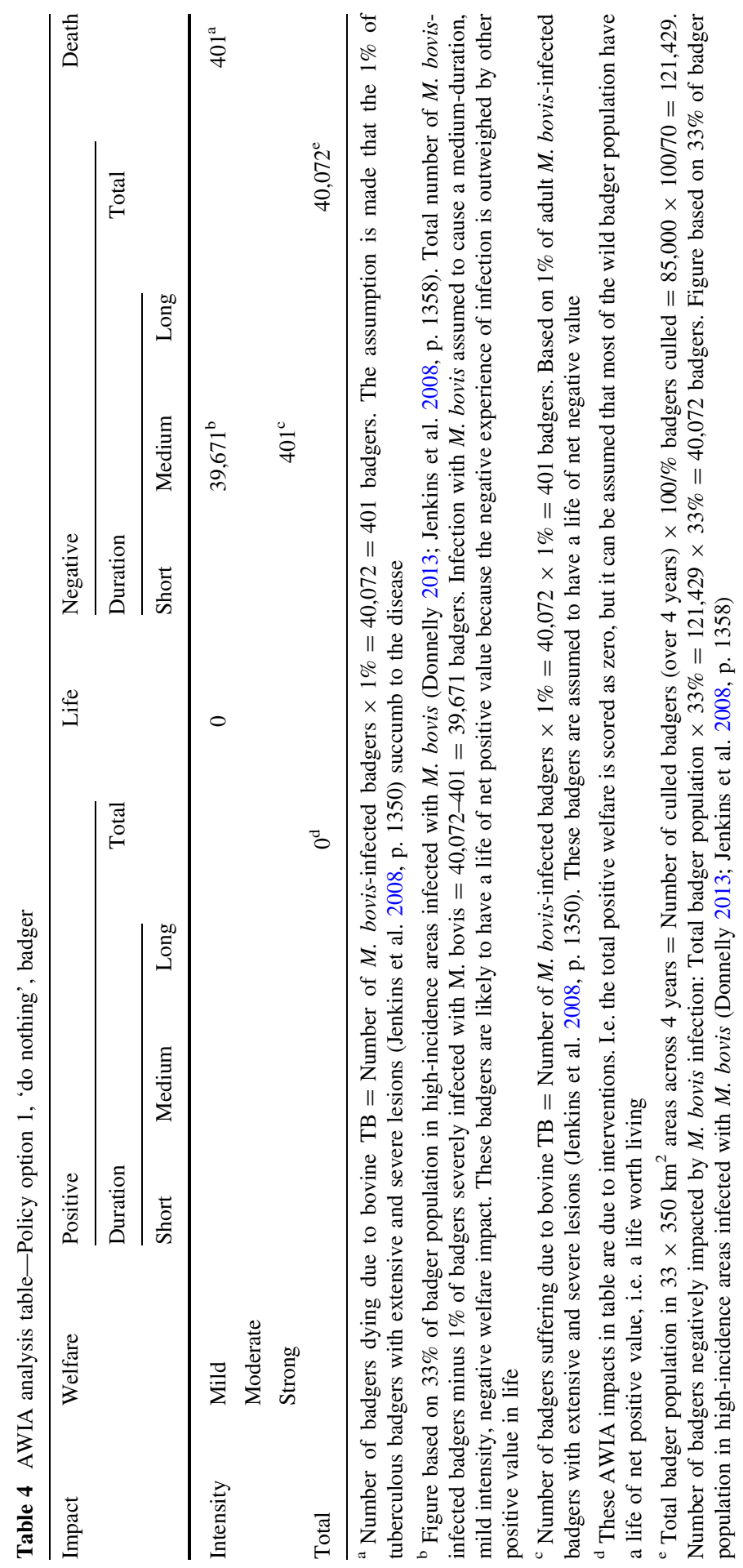




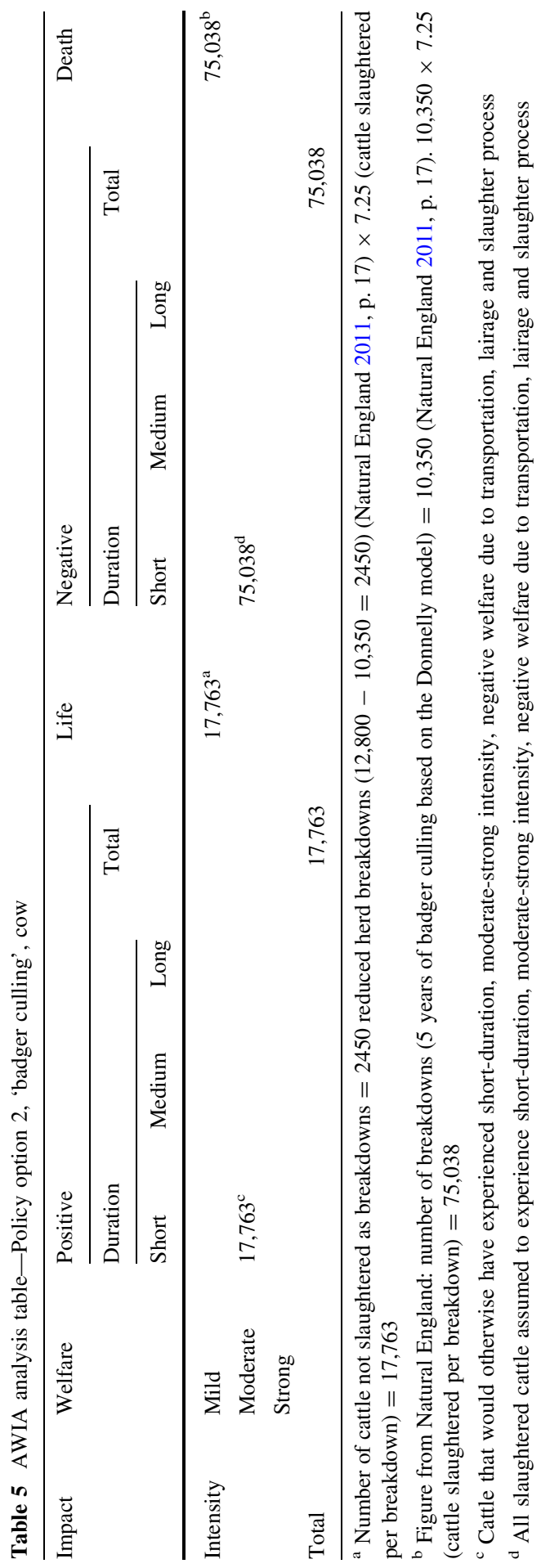




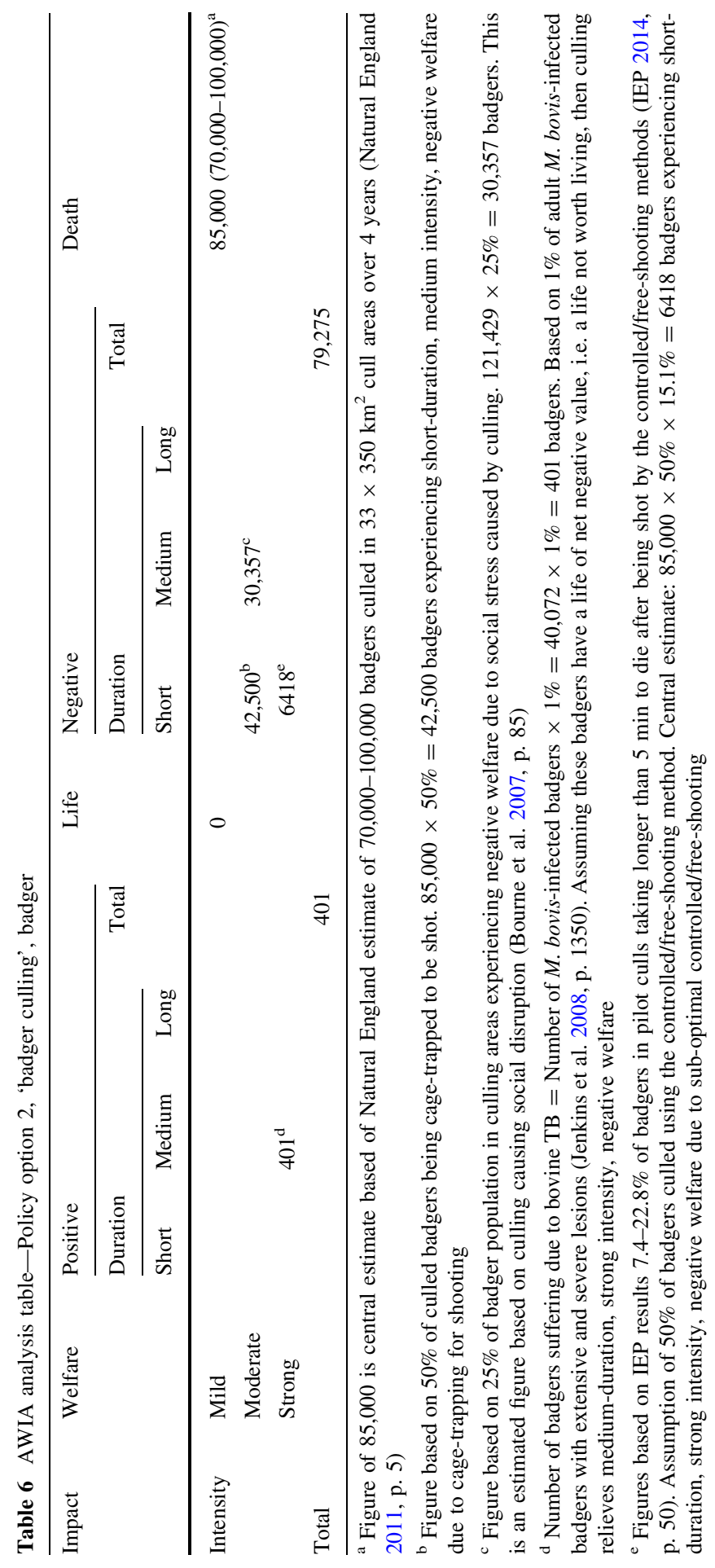


average control area of $350 \mathrm{~km}^{2}$ over a four year period. ${ }^{10}$ The $19 \%$ figure was proposed by the farming industry. It is based on the meeting of experts that was hosted by Defra to arrive at some consensus about the impact of badger culling, after the contradictory recommendations of the ISG and the King review. The 19\% figure is larger than that the $12.4-16 \%$ reduction $^{11}$ agreed at the meeting of experts, itself based on the RBCT, because the culling areas are larger $\left(350 \mathrm{~km}^{2}\right)$ than those used in the RBCT $\left(150 \mathrm{~km}^{2}\right) .{ }^{12}$

The AWIA analyses compare impacts on cattle over a policy timeframe of 9 years. The impacts on badgers are based on the four year cull at the beginning of the 9 years. Natural England states that 4 years is the minimum cull period, but is expected to be the norm (Natural England 2011, p. 5). ${ }^{13}$ Hence, since the AWIA analyses assess impacts on badgers for the 4 years of culling, this may underestimate the impacts on badgers, especially if culling licences are extended beyond 4 years. Indeed, in his report after the fourth year of culling in Somerset and Gloucestershire, the CVO recommends further annual culling to maintain the badger population at the suppressed level (Defra 2016a).

The ISG reported that $15 \%$ of road-killed badgers were infected with M. bovis. The prevalence was 16.6\% in proactive cull areas (Bourne et al. 2007, pp. 74-76). Based on ISG data, Jenkins et al. report that $14 \%$ of badgers in proactive cull areas were tuberculous (Jenkins et al. 2008, p. 1530). Jenkins et al. have documented that unpublished studies have shown that more rigorous bacteriological examinations of RBCT badgers have revealed almost twice the number of sampled badgers were infected (Jenkins et al. 2008, p. 1358). Based on the same data, Donnelly reports that about $33 \%$ of RBCT badgers were actually infected (Donnelly 2013). ${ }^{14}$ The figure of $33 \%$ of $M$. bovis-infected badgers in high incidence areas is used in this analysis.

The following sections discuss the AWIA analyses for the three policy options for badger control of (1) do nothing, (2) badger culling, and (3) badger vaccination.

\section{Policy Option 1: 'Do Nothing'}

It is standard for government to have a 'do nothing' or minimal approach in its assessment of policy options. The do-nothing policy option here refers to badgerbased measures alone. Hence, in the do-nothing policy option, bovine TB is controlled by cattle-based measures alone, such as tuberculin testing and slaughter

\footnotetext{
10 The minimum control area for a licence is $150 \mathrm{~km}^{2}$. The average application for a licence to Natural England was $350 \mathrm{~km}^{2}$ (Natural England 2011, p. 4).

11 The experts agreed that that bovine TB incidence would reduce by $3-22 \%$ (central estimate $12.4 \%$ ) if the incidence is similar inside the cull area and $2 \mathrm{~km}$ ring, or $8-24 \%$ (central estimate 16\%) assuming higher incidence inside the culling area. These figures are based on four years culling and 5.5 years postculling and the same culling methods as used in the RBCT (Defra 2011a).

12 With a larger culling zone, there is a greater ratio of the culling area to the area immediately outside. Hence, the impact of perturbation is likely to be less.

13 However, Owen Paterson MP, Secretary of State for Defra (2012-2014) during the first year of the badger culls, stated that badgers might be culled for the next 25 years (Gray 2013).

14 Professor Christl Donnelly, a member of the former ISG, is a statistical epidemiologist.
} 
of reactors, movement restrictions, slaughterhouse inspection of carcasses and onfarm biosecurity.

\section{Cattle Population Impacts}

The number of cattle slaughtered per herd breakdown is calculated by dividing the total number of cattle slaughtered by the number of new herd incidences. These figures are derived from Defra's Quarterly publication on bovine TB incidence and prevalence in Britain (Defra and GSS 2016). The figures for high risk areas in England areas are $7.78(26,185 / 3364)$ cattle slaughtered per new herd incident to end June 2016 and 6.72 (22,778/3392) to end June 2015. This analysis uses the mean of the figures for high incidence areas to end June 2015 and end June 2016, which is $7.25((7.78+6.72) / 2)$. Hence, Defra's data reveal that 7.25 cattle are slaughtered per new herd incident in high risk areas across June 2014-June 2016.

Thus, the baseline number of cattle culled in 33 high incidence areas is calculated by multiplying the estimated figure of 12,800 new breakdowns over 9 years without badger culling (Natural England 2011, p. 17) by the number of cattle culled per breakdown in high incidence areas (using Defra end June 2014-2016 figures). Hence, in the do-nothing policy option, $92,800(12,800 \times 7.25)$ cattle are estimated to be culled over a nine year timeframe.

\section{Badger Population Impacts}

The total badger population over 4 years in the 33 cull areas can be calculated based on the central estimate of 85,000 badgers culled and the objective to cull $70 \%$ of badgers. Therefore, if 85,000 is $70 \%$ of the badger population then the total badger population across 4 years in the 33 cull areas is $121,429(85,000 \times 100 / 70)$. Based on the total badger population in the 33 cull areas, estimates for welfare impacts can be made. Donnelly (2013) and Jenkins et al. (2008) report that 33\% of badgers in high bovine TB incidence areas are infected with M. bovis. Hence, 40,072 $(33 \% \times 121,429)$ badgers are infected with $M$. bovis over 4 years. Jenkins et al. found that $1 \%$ of $M$. bovis-infected badgers in the proactive areas of the RBCT had extensive and severe lesions at necropsy (Jenkins et al. 2008, p. 1350). Hence, 401 $(1 \% \times 40,072)$ badgers can be assumed to suffer medium-duration, strong intensity, negative welfare due to $M$. bovis infection. Most badgers do not suffer severely from M. bovis infection (Defra 2010b; Jenkins et al. 2008). However, it can be assumed that $M$. bovis infection does have some degree of negative impact on quality of life. Hence, the 39,671 (40,072-401) M. bovis-infected badgers that do not have severe and extensive lesions are considered to experience a medium-duration, mild intensity, negative impact on welfare. Despite this, these badgers are considered to have a life of net positive value, since the negative impact of M. bovis infection is likely to be outweighed by other positive value in life.

Finally, the AWIA analysis in this paper is concerned with assessing the impacts of the policy options of (1) do nothing, (2) badger culling, and (3) badger vaccination. For simplicity and to facilitate comparing the impact of the three policy options, it is assumed that cattle and badger populations in general have a life of net 
positive value. The assumption is to provide a baseline but is not arbitrary. To illustrate, if a cow has a life of net positive value, then $M$. bovis infection, since it leads to slaughter, causes a (very) negative impact. However, if that cow had a life of net negative value (for instance due to chronic severe lameness), infection with $M$. bovis and consequent culling would in fact be a positive impact, since her death would be the end of her suffering.

\section{Policy Option 2: 'Badger Culling'}

\section{Cattle Population Impacts}

The Natural England report to Defra includes a section on the potential benefits for bovine TB control based on industry proposals in Annex D (Natural England 2011, p. 17). The report uses the 'Donnelly model', which estimates bovine TB incidence based on 5 years of badger culling, followed by 4 years of non-culling (Jenkins et al. 2010). As the Natural England report states, because licensing criteria are based on a four year cull, using the Donnelly model may overestimate the benefits of the proposed government badger culling policy. Based on the Donnelly model, without badger culling, there would be $\sim 12,800$ new breakdowns over the nine year period in 33 control areas. Based on the Donnelly Model's 5 years of culling and a four year post-cull period, there would be $\sim 10,350$ (19\% reduction) new herd incidents, or a reduction of 2450 .

As discussed in policy option 1 , the mean number of cattle slaughtered per new herd incident from end June 2014 to 2016 is 7.25 . Hence, the total number of cattle slaughtered in the badger culling policy option is 75,038 $(10,350 \times 7.25)$ Based on these figures, a $19 \%$ reduction in bovine TB incidence due to badger culling would mean $17,763(2450 \times 7.25)$ fewer cattle slaughtered. Additional to the harm of killing, cattle culled due to bovine TB can be assumed to suffer short-duration, moderate-strong intensity, negative welfare due to the transportation, lairage and slaughter process (FAWC 2003). Thus, a 19\% reduction in bovine TB incidence results in 17,763 cattle avoiding this negative welfare impact due to being prematurely culled over a nine year timeframe. ${ }^{15}$

\section{Badger Population Impacts}

For badgers, direct non-killing welfare impacts are defined as the welfare impacts caused directly by the methods of being shot. The government controlled/freeshooting humaneness target for the pilot badger culls was fewer than 5\% of badgers taking over $5 \mathrm{~min}$ to die after being shot. The IEP reported that $7.4-22.8 \%$ of badgers took over 5 min to die (IEP 2014). The AWIA uses the central estimate of $15.1 \%$ of badgers, based on the IEP figures. The IEP also reported that cage trapping and shooting was used extensively in the pilot culls. After a Freedom of Information

\footnotetext{
${ }^{15}$ Of course, the individual cows will be culled at some point regardless. However, reduced bovine TB incidence means that fewer cows are culled, and thus fewer experience negative welfare impacts due to transportation, lairage and slaughter.
} 
Act request, it was revealed that around $75 \%$ of badgers culled in the 2013 Gloucestershire and Somerset pilot culls were cage-trapped and shot (Press Association 2014). The Defra summary report of the 2016 culls reveals that $55 \%$ of badgers were culled using controlled/free-shooting and $45 \%$ using cage-trap and shooting (Defra 2016c). The AWIA assumes that 50\% of badgers are killed by controlled/free-shooting and $50 \%$ by cage trapping and shooting across the 4 years of culling. The AWIA accounts for the welfare impacts of the $15.1 \%$ of badgers in controlled/free-shooting taking over $5 \mathrm{~min}$ to die as short-duration, strong intensity, negative welfare. Cage trapping wild animals such as badgers also causes negative welfare. The AWIA accounts for the impact of cage-trapping badgers as shortduration, moderate intensity, negative welfare.

Indirect non-killing welfare impacts are defined as welfare impacts due to the culling process other than direct impacts. Based on the RBCT, the ISG found that badger culling causes social disruption of badger groups, which leads to perturbation (Bourne et al. 2007; Woodroffe et al. 2006). The best explanation for the cause of perturbation due to the culling process is stress caused to the badger population by the activity of culling. The process of badger culling includes killing individual badgers and causing disruption of social groups due to these deaths. Further stress and perturbation is likely to result from the loud sounds of shots being fired. There are no data to quantify the indirect non-killing welfare impacts of culling, i.e. the stress caused to the local badger population. It is estimated here that $25 \%$ of the population experience indirect non-killing negative welfare due to culling causing disruption of social groups. ${ }^{16}$

\section{Policy Option 3: 'Badger Vaccination'}

There are no direct scientific data on how the BCG vaccination affects transmission of $M$. bovis from badgers to cattle. It has been shown that inoculation results in a $73.8 \%$ reduction in positive serological test results for $M$. bovis in badgers (Chambers et al. 2011, p. 1913). Defra recommends the vaccination of badgers around culling zones to reduce the impact of perturbation (Defra 2011b, p. 10). BadgerBCG can reasonably be assumed to have some positive impact on the reduction of transmission of $M$. bovis from badgers to cattle. However, there are no data to quantify this impact.

For the purpose of illustration, the AWIA analysis for badger vaccination is based on the following. First, an assumption is made that BadgerBCG reduces the transmission rate of $M$. bovis from vaccinated badgers to cattle by $50 \% .{ }^{17}$ Secondly,

\footnotetext{
16 The $25 \%$ figure is likely to be a significant underestimate, given that the target culling rate is $70 \%$ of the population. Indeed, it may be that $100 \%$ of the badger population in culling areas experience some form of negative welfare impact due to the culling process.

17 A recent study by Woodroffe et al. has revealed there to be very infrequent direct contacts between cattle and badgers on the farm environment (Woodroffe et al. 2016). The finding suggests that badger-tocattle and cattle-to-badger transmission of $M$. bovis is likely to occur through indirect contact via contamination of the species' shared environment. This evidence is an important piece in the jigsaw for the bovine TB policy evidence base. However, it should not affect this model as the assumed figure of $50 \%$ reduction in $M$. bovis transmission from badgers to cattle due to badger vaccination can result from direct or indirect contact. For instance, if badger vaccination reduces infection rates in badgers, then this
} 
Donnelly and Nouvellet report that badgers are responsible for $50 \%$ of cattle reactors in high TB-incidence areas. This includes initial badger-cattle transmission (5.7\%) and subsequent cattle-cattle transmission (94.3\%) (Donnelly and Nouvellet 2013). Using the assumption of the efficacy of BadgerBCG to reduce badger-cattle transmission rates, the findings of Donnelly and Nouvellet, and the number of badgers vaccinated, the impact of badger vaccination can be estimated. The figures in the AWIA analysis in Tables 7 and 8 are based on the vaccination of $50 \%$ of the badger population in control areas.

\section{Cattle Population Impacts}

Based on the assumptions and figures above, the impact of badger vaccination on bovine TB incidence, and thus the number of cattle culled as reactors, can be estimated. The AWIA analysis estimates that badger vaccination will result in 11,600 fewer cattle being culled over a 9 year timeframe. This figure is derived in the following way: 92,800 (cattle slaughtered, do nothing) $\times 0.5$ (badger wildlife reservoir causing $50 \%$ reactors $) \times 0.5(50 \%$ badgers vaccinated $) \times 0.5$ (assumption of BadgerBCG reduced badger-cattle transmission efficacy) $=11,600$. Thus, the number of cattle culled over a 9 year timeframe in the badger vaccination policy option is estimated to be $81,200(92,800-11,600)$.

As for the do-nothing and badger culling policy options, slaughtered cattle are assumed to experience short-duration, moderate-strong intensity, negative welfare due to transportation, lairage and slaughter process. Thus, badger vaccination results in 11,600 fewer cattle experiencing this degree of negative welfare as a result of being culled as bovine TB reactors.

\section{Badger Population Impacts}

Chambers et al. (2011, p. 1913) have shown that BadgerBCG reduces positive serological test results in badgers by $73.8 \%$. As discussed in the do-nothing policy option, Donnelly (2013) and Jenkins et al. (2008) report that $33 \%$ of badgers in proactive areas in the RBCT were infected with $M$. bovis. Around $1 \%$ of tuberculous badgers had extensive and severe lesions at necropsy (Jenkins et al. 2008). The AWIA analysis for the do-nothing policy option found that the majority of the $33 \%$ of $M$. bovis-infected badgers experience medium-duration, mild intensity, negative welfare impact. However, this is outweighed by other positive value in their lives, so this group of infected badgers still have a life of net positive value. Hence, if BadgerBCG vaccination reduces $M$. bovis infection by $\sim 75 \%(73.8 \%), 15,027$ $(121,429$ badger population $\times 33 \%$ population $M$. bovis-infected $\times 50 \%$ population vaccinated $\times 75 \%$ BadgerBCG efficacy) benefit from vaccination. Of the $1 \%$ (401) of $M$. bovis-infected badgers suffering from extensive and severe lesions in the baseline do-nothing policy, BadgerBCG results in a medium-duration, strong

Footnote 17 continued

should lead to reduced contamination of the shared environment, and thus reduced transmission of $M$. bovis to cattle. 


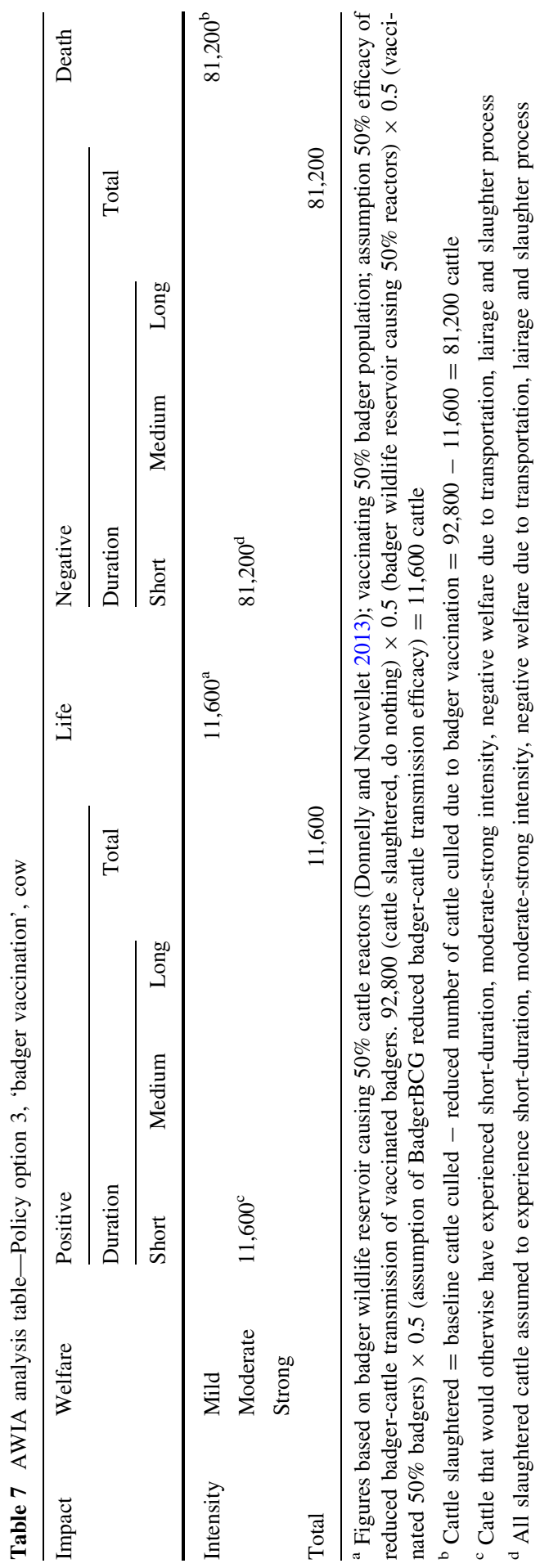




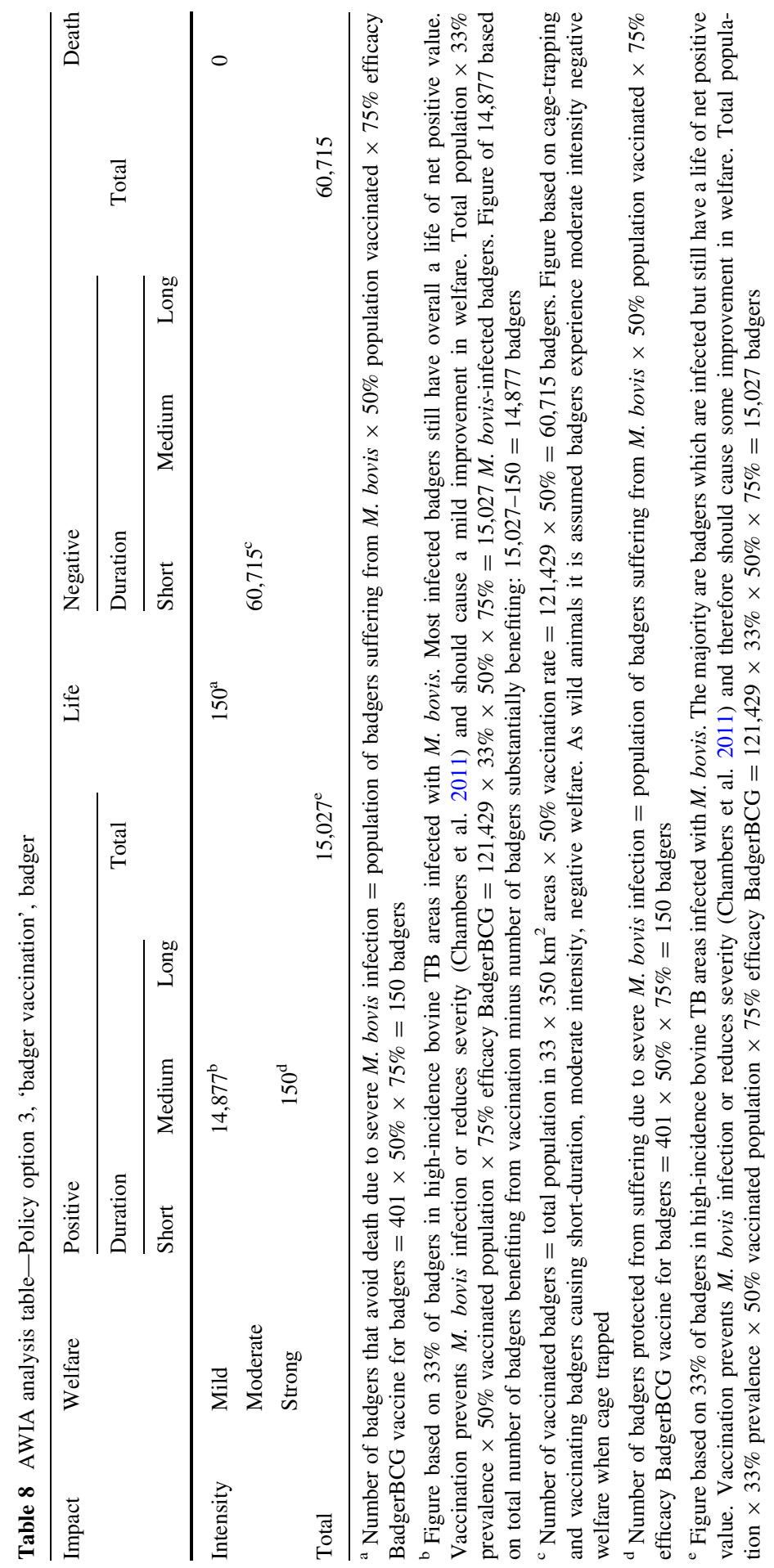


Table 9 Killing impacts of bovine TB policy options

\begin{tabular}{llccc}
\hline Policy option & $\begin{array}{l}\text { No. cattle } \\
\text { slaughtered }\end{array}$ & $\begin{array}{l}\text { No. cattle not } \\
\text { slaughtered }\end{array}$ & $\begin{array}{l}\text { No. badgers } \\
\text { culled }\end{array}$ & $\begin{array}{l}\text { Badgers culled per cow } \\
\text { that avoids slaughter }\end{array}$ \\
\hline Do nothing & 92,800 & 0 & 0 & 0 \\
$\begin{array}{l}\text { Badger culling } \\
\text { Badger }\end{array}$ & 75,038 & 17,763 & 85,000 & 4.8 \\
vaccination & 81,200 & 11,600 & 0 & 0 \\
\hline
\end{tabular}

intensity, positive welfare impact in 150 badgers (401 suffering badgers $\times 50 \%$ badger population vaccinated $\times 75 \%$ BadgerBCG efficacy). Since these badgers were assumed to die from $M$. bovis infection, BadgerBCG vaccination results in 150 badgers avoiding death. The remaining 14,877 badgers $(15,027-150)$ experience a medium-duration, mild intensity, positive welfare impact due to inoculation. Finally, the cage-trapping of wild species such as badgers can be assumed to cause moderate negative welfare. Thus, 60,715 badgers $(121,429$ total population $\times 50 \%$ population vaccinated) over a 4 year timeframe experience short-duration, moderate intensity, negative welfare due to the inoculation process.

\section{Summary of Killing Impacts of Bovine TB Policy Options}

Arguably, it is the killing impacts, for both cattle and badgers that are most relevant in AWIA of bovine TB policy options. Table 9 summarises the killing impacts of bovine TB policy options.

The 17,763 cattle not slaughtered as a result of badger culling is based on the $19 \%$ reduction in bovine TB incidence. The figure is based on Natural England's advice to Defra (Natural England 2011). Based on the AWIA vaccination policy option model and its assumptions in this analysis, badger vaccination is estimated to reduce the number of cattle culled by 11,600 , which represents a $12.5 \%$ reduction in bovine TB incidence. With respect to the badger population, the badger culling policy involves the killing of 85,000 badgers over 4 years. The number of badgers culled over the nine year policy timeframe would ultimately depend on whether culling was extended beyond the original 4-year culling licences granted by Natural England. The do-nothing and badger vaccination policies do not involve the culling of badgers.

These figures are consistent with the Natural England advice to Defra (Natural England 2011). Natural England reported that 30-50 badgers would be killed for each TB breakdown in cattle. The figures of 85,000 badgers culled to avoid the slaughter of 17,763 means that 4.785 badgers are killed for every cow which avoids slaughter. The AWIA has calculated that each herd breakdown results in $\sim 7.25$ cattle slaughtered. Hence, $34.69(4.785 \times 7.25)$ badgers are culled to prevent each bovine TB herd breakdown in cattle. 


\section{Animal Health and Welfare Policy Actors on AWIA}

As part of the research undertaken for the project which this paper is based on, the first author conducted semi-structured interviews with animal health and welfare policy actors. The AWIA is a policy instrument to be used to analyse impacts on sentient animals in public policy. For this reason, elites in animal health and welfare policy were asked about their views on a potential AWIA tool. ${ }^{18}$ The interviews were conducted between 2012 and 2013 and 17 individuals were interviewed. Interviewees were selected primarily based on their roles giving them knowledge of the animal health and welfare policy process. They included former government ministers, Defra civil servants, a farming industry official, a senior veterinary surgeon, a scientific expert and an animal welfare NGO official. Interviewees were given the option of whether to be identified in the research output or to remain anonymous. Hence, in the quotations from transcripts below, some actors are identified, whereas others are labelled with reference to their professional role and affiliation. Interviews, which were digitally audio-recorded, lasted for around an hour and the material was transcribed and thematically coded for analysis. The interviews covered a range of issues related to the broader project and the question about AWIA was just one part of the interview. Quotations from transcripts below include references to bovine $\mathrm{TB}$ because the policy issue in general was also discussed during the interview. Interviewees were asked their opinions on the concept of AWIA and they were not commenting on the AWIA application to bovine TB policy presented in this paper.

In general, there was broad support for the concept of AWIA. A former British Cattle Veterinary Association (BCVA) President stated:

What I think you're trying to do is get some objective information, for something like what's the welfare impact of a public policy, and I think that has to be a good thing. The better informed and the more objective the data to hand or the information to hand, that has to be a good thing. So in principle I would welcome it. [Former President, BCVA].

A National Farmers Union (NFU) TB policy official agreed in principle with the use of an AWIA tool:

Interviewer: So the question is what, either the NFU position if you can speak on behalf of the NFU, or your position as an individual, would you agree to that sort of policy tool [AWIA] in principle?

Yeah. I mean I've got no problem. I mean most farmers would say, is it right ethically, welfare-wise, to kill $30+$ thousand cattle every year, that would be normally healthy cattle?. Whether they might be close to calving, have calves

\footnotetext{
18 A participant information sheet was sent to interviewees prior to the interview. The information included the following: "The AWIA can be thought of as an envelope of various tools and procedures used to appraise the impact on animals in the policy process. At its simplest it is an estimate of the number of animals impacted by each policy option in terms of quantity killed and negative welfare impacts. The tool can be developed to incorporate positive impacts on animals and estimates of the intensity of impacts (mild, moderate and severe)".
} 
inside them. You know, [that] can't be right, when we're expecting to kill 5,000 badgers, when 50,000 of them are killed on the road each year. [NFU official, TB policy].

The Compassion in World Farming (CIWF) Chief Executive related AWIA to intrinsic moral considerations:

I would certainly think that an objective assessment of animal welfare in its proper sense rather than just its animal health sense would be a very important tool. I totally agree that the intrinsic moral worth of animals needs to be addressed, needs to be recognised. [Philip Lymbery, CEO CIWF].

A former Conservative Defra minister was more lukewarm about the idea:

I don't dissent from the idea, I'm always just cautious of yet another process to go through before decisions are made and policies are got on with. So often delay is the enemy of progress and getting things done. And I mean I suppose you would rightly argue that an impact assessment would address it, but quite often there are ups and downs. I mean if you take the TB issue, you know, a lot of the people would argue it is about badger welfare. Actually, it's a very big issue about cattle welfare, and you know to do an assessment properly would have to take into account both sides of that. [Former Defra minister, Conservative Party].

The Chair of the All-Party Parliamentary Group for Animal Welfare (APGAW) supported AWIA but believed it should be conducted by an independent body:

You'd have to make sure it had the confidence of the public and it had the very best scientific people on it, because otherwise you see it would be challenged, and then you'd go straight back into the political arena. You will anyway to a degree, but the only way you will get trust is through having a good strong scientific base for it. [Neil Parish MP, Chair APGAW].

An Animal Health Veterinary Laboratories Agency (AHVLA) ${ }^{19}$ official advised that for it to be done it would have to be compulsory. The official advised that the AWIA should not be too simple but also not too complicated, and considered it useful to provide some structure to the assessment of policy impacts [Civil servant, AHVLA]. The AWIA has been constructed so that it can be completed to varying degrees of detail to account for the AHVLA official's point.

A second former Defra minister interviewed discussed the idea that policy impacts on animals are currently assessed on a "case-by-case" basis [Former Defra minister, Labour Party]. We would argue that the current approach of assessment on a case-by-case basis is not sufficiently rigorous. Such an approach permits policy makers to omit, whether intentional or otherwise, policy impacts that are of critical importance to sentient animals and public concern. For instance, the impact assessment on badger culling focuses on the humaneness of culling methods and

19 The AHVLA was the Defra agency responsible for animal health and welfare policy at the time the interviews were conducted. At the time of writing in July 2017, the Defra agency responsible for animal health and welfare is the Animal and Plant Health Agency (APHA). 
ecological issues ${ }^{20}$ (Defra 2011d). However, the public's principal moral concern relates to the moral issue of killing badgers (Bennett and Willis 2008; Defra 2006a, 2006b). Despite this, government policy statements pay scant attention to this issue (Defra 2011c, p. 15).

\section{Discussion}

The paper has argued for the mandatory application of formal and systematic Animal Welfare Impact Assessment (AWIA) to all policy options which potentially impact the interests of sentient animals. The justification for requiring mandatory AWIA in policy making is based on the following arguments: (1) sentient animals are owed direct moral consideration based on their subjective experiential lives (sentient animals can have a life worth living or a life of suffering); (2) there is widespread and consistent public concern about how public policy impacts animals; and (3) the Treaty of Lisbon, which amends the founding Treaty of the EU, recognises that (certain) animals are sentient and mandates member states to pay full regard to such animals in policy making.

The AWIA should be conducted in three stages for each species impacted by policy: (1) species description, (2) harms and benefits list; and (3) AWIA analysis. This paper applies AWIA to bovine TB and badger control in England. It demonstrates how AWIA can illustrate positive and negative welfare impacts, and life and killing impacts, for a number of policy options on a number of species. Such a policy tool is a necessary element of evidence-based policy making in animal health and welfare policy.

In bovine TB policy, based on Natural England data and industry figures for a 19\% reduction in bovine TB incidence (Natural England 2011), the AWIA reveals that the badger culling policy results in a far greater number of badgers killed $(\sim 85,000)$ over a four year period compared to the number of cattle $(\sim 17,750)$ that would otherwise be slaughtered as TB reactors over a nine year period. These figures translate to about five (4.8) badgers culled for every cow which avoids slaughter due to bovine TB. In addition, the badger culling policy causes greater direct and indirect welfare impacts associated with the culling process. Direct welfare impacts are caused by badgers suffering as a result of being shot and not dying instantaneously. Indirect welfare impacts are caused by the disruption of social groups as a result of badgers being shot, and disturbance to the badger populations, particularly due to the noise arising from the culling process.

To assess the impact of vaccination the analysis uses a set of stated assumptions. These are (1) that BadgerBCG reduces the transmission rate of $M$. bovis from badgers to cattle by $50 \%$, (2) that badgers are responsible for $50 \%$ of cattle TB reactors in high risk areas, and (3) that $50 \%$ of the badger population in high risk areas are vaccinated. Based on this model, the AWIA reveals that badger vaccination has the potential to have a lesser but similar impact on reducing the number of cattle slaughtered $(\sim 11,600)$, compared to badger culling $(\sim 17,750)$. Badgers are not killed in the

\footnotetext{
${ }^{20}$ I.e. the impact of culling on badgers as a species, not as individual sentient animals.
} 
badger vaccination policy options, and the welfare impacts are considerably less severe compared to those associated with badger culling.

Finally, when comparing the impacts of badger control policy options, it is important to remember the underlying assumptions in the AWIA. The proposed $19 \%$ reduction in bovine TB incidence in cattle due to badger culling is based on killing over $70 \%$ of the badger population in culling areas. However, the IEP reported that the 2013 pilot badger culls in Somerset $(<48 \%)$ and Gloucester $(<39 \%)$ fell far short of the $70 \%$ target in the original six-week licences for culling (IEP 2014). The failure to cull $70 \%$ of the badger population and the extensions to the culling times are likely to have limited the efficacy of badger culling in reducing the incidence of bovine TB in cattle.

There is considerable uncertainty as to the efficacy of vaccinating badgers, in terms both of protecting badgers against $M$. bovis infection and of transmitting the disease to cattle. The analysis in this paper has sought to use conservative estimates of efficacy. For instance, although Chambers et al. have reported a 73.8\% reduction in seroprevalence in badgers vaccinated with BCG (Chambers et al. 2011), the AWIA assumes that badger vaccination reduces the transmission rate from a vaccinated badger to cattle by $50 \%$. However, from a practical standpoint, it is worth noting that badger vaccination with BadgerBCG must be conducted annually, which raises questions about its feasibility as a medium-long term policy option. Of course, this must be compared to badger culling, which is unlikely to be socially acceptable in the medium-long term.

In interviews conducted as part of the research, animal health and welfare policy actors were supportive of the idea of AWIA. Interviewees pointed to the need for objective data and for the analysis to be conducted impartially to gain the respect of the policy community. The results of the AWIA are used to inform the ethical analysis of bovine TB and badger control policy options. Elsewhere, utilitarian (McCulloch and Reiss 2017b), animal rights (McCulloch and Reiss 2017c) and virtue-based frameworks (McCulloch and Reiss 2017d) have been applied to the AWIA in this paper.

Acknowledgements The first author would like to thank the Royal Veterinary College, which funded work for a $\mathrm{PhD}$ project that this paper is based on. He would also like to thank animal health and welfare policy actors interviewed during the course of the research. We would like to thank the late Christopher Wathes, who supervised the earlier part of the first author's $\mathrm{PhD}$ research, which this paper is based on.

Open Access This article is distributed under the terms of the Creative Commons Attribution 4.0 International License (http://creativecommons.org/licenses/by/4.0/), which permits unrestricted use, distribution, and reproduction in any medium, provided you give appropriate credit to the original author(s) and the source, provide a link to the Creative Commons license, and indicate if changes were made.

\section{References}

Bateson, P., Begon, M., Blackburn, T., Bourne, J., Sutherland, W., Burke, T., \& Woodroffe, R. (2012). Culling badgers could increase the problem of TB in cattle: Badger culling risks becoming a costly 
distraction from nationwide TB control. The Observer. Retrieved from http://www.theguardian.com/ theobserver/2012/oct/14/letters-observer?guni=Article:in\%20body\%20link.

Battersby, J., \& Tracking Mammals Partnership. (2005). UK Mammals: Species Status and Population Trends. First Report by the Tracking Mammals Partnership. Peterborough: JNCC/Tracking Mammals Partnership.

BBC. (2016). Badger cull extended to more English counties. Retrieved from http://www.bbc.co.uk/ news/uk-england-37220043.

Bennett, R., \& Willis, K. (2008). Public values for badgers, bovine TB reduction and management strategies. Journal of Environmental Planning and Management, 51(4), 511-523. doi:10.1080/ 09640560802116996.

BIS. (2011a). IA Toolkit: How to do an Impact Assessment. London: Department of Business, Innovation and Skills.

BIS. (2011b). Impact Assessment Guidance: When to do an Impact Assessment. London: Department of Business, Innovation and Skills.

Bourne, F. J., Donnelly, C. A., Cox, D. R., Gettinby, G., McInerney, J. P., Morrison, W. I., \& Woodroffe, R. (2007). Bovine TB: The Scientific Evidence-Final Report of the Independent Scientific Group on Cattle TB. London: Independent Scientific Group on Cattle TB.

Boyd, I., \& Gibbens, N. (2012). Badger cull furore is distracting attention from the real problem. The Guardian. Retrieved from http://www.theguardian.com/environment/2012/oct/11/badger-cullfurore.

British Wildlife Centre. (2012). British Wildlife Species Collection: Badger-Meles meles. Retrieved 1 February, 2015, from http://www.britishwildlifecentre.co.uk/planyourvisit/animals/badger.html.

Chambers, M. A., Rogers, F., Delahay, R. J., Lesellier, S., Ashford, R., Dalley, D., et al. (2011). Bacillus Calmette-Guérin vaccination reduces the severity and progression of tuberculosis in badgers. Proceedings of the Royal Society B: Biological Sciences, 278(1713), 1913-1920.

DairyCo. (2014a). UK Cow Numbers. Retrieved 2 February, 2015, from http://www.dairyco.org.uk/ market-information/farming-data/cow-numbers/uk-cow-numbers/.

DairyCo. (2014b). World dairy cow numbers. Jan 2014. Retrieved 2 April, 2014, from http://www. dairyco.org.uk/market-information/farming-data/cow-numbers/world-cow-numbers/.

Dawkins, M. S. (2006). Through animal eyes: what behaviour tells us. Applied Animal Behaviour Science, $100(1), 4-10$.

Defra. (2006a). Public Consultation on Controlling the Spread of Bovine Tuberculosis in Cattle in High Incidence Areas in England: Badger Culling-A Report on the Citizens' Panels London: Defra.

Defra. (2006b). Public Consultation on Controlling the Spread of Bovine Tuberculosis in Cattle in High Incidence Areas in England: Badger Culling-Summary of Responses. London: Defra.

Defra. (2010a). Bovine Tuberculosis: The Government's approach to tackling the disease and consultation on a badger control policy. London: Defra.

Defra. (2010b). Bovine Tuberculosis: The Government's approach to tackling the disease and consultation on a badger control policy-Annex $G, Q \& A$. London: Defra.

Defra. (2011a). Bovine TB-Key conclusions from the meeting of scientific experts, held at Defra on 4th April 2011. London: Defra.

Defra. (2011b). Bovine TB Eradication Programme for England. London: Defra.

Defra. (2011c). The Government's policy on Bovine TB and badger control in England. London: Defra.

Defra. (2011d). Measures to address bovine TB in badgers: Impact Assessment. London: Defra.

Defra. (2013). Farming Statistics-Livestock Populations at 1st December 2012, UK and England. London: Defra Retrieved from https://www.gov.uk/government/uploads/system/uploads/ attachment_data/file/183227/defra-stats-foodfarm-landuselivestock-farmstats-dec2012-130314.pdf.

Defra. (2014). Farming Statistics_Livestock Populations at 1 December 2013, England. London: Defra Retrieved from https://www.gov.uk/government/uploads/system/uploads/attachment_data/file/286876/ structure-dec2013-eng-06mar14.pdf.

Defra. (2016a). Chief Veterinary Officer's advice on the outcome of the 2016 badger culls. London: Defra.

Defra. (2016b). Further measures to eradicate bovine TB [Press release]. Retrieved from https://www. gov.uk/government/news/further-measures-to-eradicate-bovine-tb.

Defra. (2016c). Summary of badger control monitoring during 2016. London: Defra.

Defra, \& GSS. (2016). Quarterly publication of National Statistics on the incidence and prevalence of tuberculosis (TB) in Cattle in Great Britain-to end June 2016. London: Office for National Statistics. 
DeGrazia, D. (1996). Taking animals seriously: Mental life and moral status. Cambridge: Cambridge University Press.

Donnelly, C. (2013, Oct 11). The badger cull—key science questions answered. The Guardian. Retrieved from http://www.theguardian.com/environment/2013/oct/11/badger-cull-key-science-questionsanswered.

Donnelly, C. A., \& Nouvellet, P. (2013). The contribution of badgers to confirmed tuberculosis in cattle in high-incidence areas in England. PLOS Currents Outbreaks. doi:10.1371/currents.outbreaks. 097a904d3f3619db2fe78d24bc776098.

Duncan, I. J. (2006). The changing concept of animal sentience. Applied Animal Behaviour Science, $100(1), 11-19$.

FAO. (2010). Statistical Yearbook of the Food and Agricultural Organization: Food and Agricultural Organization.

FAWC. (2003). Report on the Welfare of Farmed Animals at Slaughter or Killing. London: Farm Animal Welfare Council.

FAWC. (2009a). Farm animal welfare in Great Britain: Past, present and future. London: Farm Animal Welfare Council.

FAWC. (2009b). Opinion on the welfare of the dairy cow. London: Farm Animal Welfare Council.

Godwin-Pearson, G. (2012). Common Sense and Bovine TB: Why the Government should abandon badger culling trials in favour of vaccination. London: The Bow Group.

Gray, L. (2013). Badger cull 'could last 25 years'. The Telegraph. Retrieved from http://www.telegraph. co.uk/news/earth/wildlife/10081604/Badger-cull-could-last-25-years.html.

HM Gov. (2010). The Coalition: Our programme for government. London: The Cabinet Office.

HM Gov. (2013). Stop the Badger Cull: e-petition. Retrieved 2 Jan 2017 http://epetitions.direct.gov.uk/ petitions/38257.

IEP. (2014). Pilot Badger Culls in Somerset and Gloucestershire: Report by the Independent Expert Panel. London: Independent Expert Panel.

Jenkins, H. E., Morrison, W. I., Cox, D. R., Donnelly, C. A., Johnston, W. T., Bourne, F. J., et al. (2008). The prevalence, distribution and severity of detectable pathological lesions in badgers naturally infected with Mycobacterium bovis. Epidemiology and Infection, 136(10), 1350-1361.

Jenkins, H. E., Woodroffe, R., \& Donnelly, C. A. (2010). The duration of the effects of repeated widespread badger culling on cattle tuberculosis following the cessation of culling. PLoS ONE. doi:10.1371/journal.pone.0009090.

King, D. (2007). Bovine tuberculosis in cattle and badgers. London: Defra.

Krebs, J. R., Anderson, R., Clutton-Brock, T., Morrison, I., Young, D., \& Donnelly, C. (1997). Bovine Tuberculosis in Cattle and Badgers. London: Independent Scientific Review Group.

McCulloch, S. P., \& Reiss, M. J. (2017a). Bovine Tuberculosis and Badger Control in England: Science, Policy and Politics. Journal of Agricultural \& Environmental Ethics. https://doi.org/10.1007/ s10806-017-9679-2

McCulloch, S. P., \& Reiss, M. J. (2017b). Bovine Tuberculosis and Badger Culling in England: A Utilitarian Analysis of Policy Options. Journal of Agricultural \& Environmental Ethics. https://doi. org/10.1007/s10806-017-9680-9.

McCulloch, S. P., \& Reiss, M. J. (2017c). Bovine Tuberculosis and Badger Culling in England: An Animal Rights-Based Analysis of Policy Options. Journal of Agricultural \& Environmental Ethics. https://doi.org/10.1007/s10806-017-9683-6

McCulloch, S. P., \& Reiss, M. J. (2017d). Bovine Tuberculosis Policy in England: Would a Virtuous Government Cull Mr Badger? Journal of Agricultural \& Environmental Ethics. https://doi.org/10. 1007/s10806-017-9682-7

Messenger, S. (2016). 'Refreshed' bovine TB policy includes targeting infected badgers. BBC News,. Retrieved from http://www.bbc.co.uk/news/uk-wales-37679272.

Natural England. (2011). The impact of culling on badger (Meles meles) populations in England and measures to prevent their 'local disappearance' from culled areas: Supplementary advice provided under the Protection of Badgers Act 1992 and Wildlife \& Countryside Act 1981 (as amended): Natural England.

Press Association. (2014, 23 Jan). Badger cull killed only 24\% of animals by controlled shooting, figures show. The Guardian. Retrieved from http://www.theguardian.com/environment/2014/jan/23/ badger-cull-only-quarter-controlled-shooting.

Radford, M. (2001). Animal welfare law in britain: Regulation and responsibility. Oxford: Oxford University Press. 
Reynolds, D. (2006). A review of tuberculosis science and policy in Great Britain. Veterinary Microbiology, 112(2), 119-126.

Ryder, R. D. (2000). Animal revolution: Changing attitudes towards speciesism. Oxford: Berg.

Spencer, A. (2011). One body of evidence, three different policies: bovine tuberculosis policy in Britain. Politics, 31(2), 91-99.

Truss, E. (2015). Environment Minister addresses the Oxford Farming Conference. Retrieved from https:// www.gov.uk/government/speeches/environment-minister-addresses-the-oxford-farming-conference-2.

Wang, A. (2011). Meles meles: Eurasian badger. Available from University of Michigan Animal Diversity Web Retrieved 5 February 2015 http://animaldiversity.ummz.umich.edu/accounts/Meles_ meles/\#lifespan_longevity.

WildCRU. (2015). Research: The Badger Project. Retrieved 5 February 2015, 2015, from http://www. wildcru.org/research/the-badger-project/.

Wilson, G., Harris, S., \& McLaren, G. (1997). Changes in the British badger population, 1988-1997. London: People's Trust for Endangered Species.

Woodroffe, R., Donnelly, C. A., Cox, D. R., Bourne, F. J., Cheeseman, C. L., Delahay, R. J., et al. (2006). Effects of culling on badger Meles meles spatial organization: implications for the control of bovine tuberculosis. Journal of Applied Ecology, 43(1), 1-10. doi:10.1111/j.1365-2664.2005.01144.x.

Woodroffe, R., Donnelly, C. A., Ham, C., Jackson, S. Y. B., Moyes, K., Chapman, K., et al. (2016). Badgers prefer cattle pasture but avoid cattle: implications for bovine tuberculosis control. Ecology Letters, 19(10), 1201-1208. doi:10.1111/ele.12654. 